\title{
Review Article \\ Renoprotective Effects of Incretin-Based Therapy in Diabetes Mellitus
}

\author{
Habib Yaribeygi, ${ }^{1}$ Stephen L. Atkin $(1),{ }^{2}$ Fabrizio Montecucco $\left(\mathbb{D},{ }^{3,4}\right.$ Tannaz Jamialahmadi, ${ }^{5,6}$ \\ and Amirhossein Sahebkar $\oplus^{7,8,9,10}$ \\ ${ }^{1}$ Research Center of Physiology, Semnan University of Medical Sciences, Semnan, Iran \\ ${ }^{2}$ Weill Cornell Medicine Qatar, Doha, Qatar \\ ${ }^{3}$ IRCCS Ospedale Policlinico San Martino Genoa-Italian Cardiovascular Network, 10 Largo Benzi, 16132 Genoa, Italy \\ ${ }^{4}$ First Clinic of Internal Medicine, Department of Internal Medicine, University of Genoa, 6 Viale Benedetto XV, 16132 Genoa, Italy \\ ${ }^{5}$ Department of Food Science and Technology, Quchan Branch, Islamic Azad University, Quchan, Iran \\ ${ }^{6}$ Department of Nutrition, Faculty of Medicine, Mashhad University of Medical Sciences, Mashhad, Iran \\ ${ }^{7}$ Biotechnology Research Center, Pharmaceutical Technology Institute, Mashhad University of Medical Sciences, Mashhad, Iran \\ ${ }^{8}$ Applied Biomedical Research Center, Mashhad University of Medical Sciences, Mashhad, Iran \\ ${ }^{9}$ School of Pharmacy, Mashhad University of Medical Sciences, Mashhad, Iran \\ ${ }^{10}$ Department of Medical Biotechnology, School of Medicine, Mashhad University of Medical Sciences, Mashhad, Iran
}

Correspondence should be addressed to Amirhossein Sahebkar; amir_saheb2000@yahoo.com

Received 22 April 2021; Revised 5 July 2021; Accepted 29 July 2021; Published 23 August 2021

Academic Editor: Naoaki Sakata

Copyright (C) 2021 Habib Yaribeygi et al. This is an open access article distributed under the Creative Commons Attribution License, which permits unrestricted use, distribution, and reproduction in any medium, provided the original work is properly cited.

\begin{abstract}
Glucagon-like peptide-1 (GLP-1) receptor agonists are recently discovered antidiabetic drugs with potent hypoglycemic effects. Among different mechanisms of activity, these compounds were shown to reduce blood glucose by suppression of glucagon secretion and stimulation of glucose-dependent insulin secretion. These antidiabetic agents have a minor risk of hypoglycemia and have been suggested as a second-line therapy to be added to metformin treatment to further optimize glycemic control in diabetes. More recently, scientific evidence suggests that GLP-1 receptor agonists may particularly afford protection from diabetic nephropathy through modulation of the molecular pathways involved in renal impairment and so improve renal function. This additional benefit adds further weight for these compounds to become promising drugs not only for glycemic control but also to prevent diabetic complications. In this review, we have updated evidence on the beneficial effects of GLP-1 receptor agonists on diabetic nephropathy and detailed the underlying pathophysiological mechanisms.
\end{abstract}

\section{Introduction}

The global prevalence of all types of diabetes mellitus (DM) is increasing [1]. This metabolic disorder is accompanied by not only deteriorating metabolism of glucose but also lipids and amino acids $[1,2]$. On the other hand, DM is also associated with other pathophysiologic molecular mechanisms including oxidative stress, inflammatory responses, and apoptosis. This results in aberrant metabolic pathways, involving polyol, hexokinases activation, cell death receptor activity, modulation of different transcription factors and protein kinases, and other molecular mechanisms such as renin- angiotensin system (RAS) activation and autonomic nervous system (ANS) effects [3]. Therefore, all diabetic complications including the microvascular diabetic complications of diabetic nephropathy $(\mathrm{DN})$, diabetic retinopathy $(\mathrm{DR})$ and diabetic neuropathy, and macrovascular disease such as cardiovascular disorders have been recently hypothesized to be caused by a combination of abnormal glucose levels and the above-cited mechanisms [4].

Glucagon-like peptide-1 receptor (GLP-1R) agonists are novel antidiabetic drugs that have potent hypoglycemic effects and reduce blood glucose by suppression of glucagon secretion and through glucose-dependent insulin secretion 
$[5,6]$. These antidiabetic agents have a minor risk of hypoglycemia and have been suggested as second-line therapy to be added to metformin treatment to optimize glycemic control in diabetes [7]. Alternatively, dipeptidyl peptidase-4 inhibitors (DPP-4i) may be used to prevent the degradation of endogenous GLP-1 leading to its prolonged activity [8].

There is now recent evidence suggesting that these agents may prevent DN [9-11]. In this review, we have presented the evidence for the beneficial effect of glucagon-like peptide-1 receptor agonists on diabetic nephropathy and detailed the underlying molecular mechanisms involved in its pathophysiology. These agents may provide further protection of the kidney by indirect and "pleiotropic" effects in addition to optimizing glycemic control [12].

\section{Glucagon-Like Peptide Receptors and Related Analogues}

Glucagon-like peptide-1 (GLP-1) is a protein belonging to the incretin family that is released from the intestine in response to food ingestion [13]. GLP-1R is found on pancreatic islets' beta cells and is involved in the control of glycemia by induction of insulin release and suppression of glucagon secretion [14]. In humans, it is synthesized by the GLP-1R gene that is located on chromosome $6[15,16]$. GLP-1R is a member of the glucagon receptor family of $\mathrm{G}$ protein-coupled receptors that are composed of two domains, an extracellular domain that binds the C-terminal helix of GLP-1, and a transmembrane domain that binds to the N-terminal region of GLP-1 [17-20]. Incretin therapy for diabetes control is based on GLP-1R agonists and DPP-4i whose glycemic effects are mediated by these receptors (Table 1 ) $[5,21]$. GLP-1R agonists are a class of recently introduced antidiabetic drugs that were approved by the FDA in 2010 for the treatment of diabetic patients [21]. The incretin family includes intestinal GLP-1 and gastric inhibitory peptide (GIP), which reduce postprandial blood glucose by inhibition of glucagon secretion from pancreatic $\alpha$-cells and stimulate insulin release from $\beta$-cell in a glucose-dependent manner [22-24]. Moreover, they can have additional effects, such as delaying gastric emptying, suppression of appetite, decreased nutrient absorption from the gut, improvement of lipid metabolism, and inhibition of pancreatic $\beta$-cell apoptosis $[23,25,26]$. GLP-1R activation is followed by increased production of cAMP (cyclic adenosine monophosphate), cellular depolarization, and an increase in intracellular calcium concentration leading to insulin secretion from pancreatic $\beta$-cells $[24,27]$.

DPP-4 is a ubiquitous enzyme that is widely distributed [28]. DPP-4 inhibitors have their hypoglycemic effect by preventing endogenous GLP-1 inactivation leading to glucosedependent insulin release from islet $\beta$-cells and glucagon release suppression [8]. After posttranslational processing of preglucagon (PG) peptides in the intestinal L cells, at least four separate forms of $\mathrm{PG}$ are secreted that all can be inactivated by DPP-4 by removing the two amino acids from the N-terminal residue [29]. Therefore, DPP-4i have a similar hypoglycemic mechanism to GLP-1 agonists, although GLP-1 agonists have been hypothesized to affect additional pleiotropic effects, may reduce body weight, and improve metabolic variables [8].

\section{Molecular Mechanisms Involved in the Pathophysiology of DN}

Renal dysfunction in diabetic patients is common with a high prevalence of up to 40 percent and underlies the development of end-stage renal disease (ESRD) leading to complete renal failure requiring hemodialysis $[30,31]$. DN pathophysiology includes alteration of several molecular pathways, such as oxidative damage, inflammatory responses, apoptosis, protein kinase c (PKC), renin-angiotensin system (RAS) activation, adenosine, toll-like receptor (TLR) activation, transforming growth factor- $\beta$ (TGF- $\beta$ ), nitric oxide (NO) synthesis, tumor necrosis factor- $\alpha$ (TNF- $\alpha$ ), death receptors, JAK/STAT (Janus kinase/signal transducers and activators of transcription) pathway, and different types of adhesion molecules [3, 32]. Agents that can modulate these pathways may provide beneficial effects for improving renal function $[2,21,33]$.

\section{Renoprotective Effects of GLP-1R Agonists}

GLP-1R induction has been reported to protect renal tissue and improve kidney function from diabetes-induced dysfunction via several molecular mechanisms [9-11] that have been detailed in the following paragraphs (Figure 1).

4.1. Antioxidant Activity. DM has been associated with higher levels of oxidants and free radical production in different organs including renal tissue $[21,34,35]$. There is increasing evidence indicating that GLP-1R induction might attenuate oxidative markers and ameliorate oxidative damage [36-39]. $\mathrm{Wu}$ and colleagues in 2011 demonstrated that treatment with the GLP-1R agonist exenatide decreased oxidative stress markers in diabetic patients [38]. Bunck and coworkers in 2010 reported that 51-week therapy with exenatide was associated with significant reduction in oxidative stress markers of malondialdehyde (MDA) and oxidized low-density lipoprotein (oxLDL) in diabetic patients [36]. The authors suggested that the antioxidative effects of this drug might be related to the lowering of postprandial glucose [36].

Chang and colleagues in 2013 reported that exenatide therapy markedly reduces IR- (ischemia-reperfusion-) induced oxidative stress in both in vitro and in vivo models [37]. The authors showed that exenatide was able to directly inhibit $\mathrm{H}_{2} \mathrm{O}_{2}$-induced free radical species production and decrease the levels of lactate dehydrogenase $(\mathrm{LDH})$, creatine kinase-MB (CK-MB), and MDA, whilst potentiating the antioxidant defense system elements of superoxide dismutase (SOD) [37]. Moreover, Holz in 2004 suggested that GLP-1R induction led to its antioxidant effects by cAMP- (cyclic adenosine monophosphate-) dependent pathways [40]. Similarly, there is evidence for comparable effects of DPP-4i [11, 41, 42]. Pujadas and coworkers reported that the DPP-4i teneligliptin acts as a potent antioxidant agent, potentiating the antioxidant defense system and reducing NADPH (nicotinamide adenine dinucleotide phosphate) oxidase-induced free radical species, reducing oxidative damage in human umbilical vein endothelial cells [41].

On the other hand, GLP-1R induction can be achieved via the NRF2 (nuclear factor [erythroid-derived 2]-like 2) signaling pathway $[13,41]$. NRF2 is a main regulator of gene 
TABLE 1: GLP-1RA and DPP-4i families.

\begin{tabular}{lcc}
\hline Class of drugs & Approved forms & Effects \\
\hline GLP-1RA & $\begin{array}{c}\text { Exenatide, liraglutide, albiglutide, semaglutide, } \\
\text { lixisenatide, and dulaglutide }\end{array}$ & $\begin{array}{c}\text { Directly induce GLP-1R activity and mimetic incretin } \\
\text { hormone hypoglycemic effects }\end{array}$ \\
DPP-4i & Sitagliptin, vildagliptin, saxagliptin, linagliptin & $\begin{array}{c}\text { Block the DPP-4 enzyme activity and thereby increase the } \\
\text { active levels of GLP-1 }\end{array}$ \\
\hline
\end{tabular}

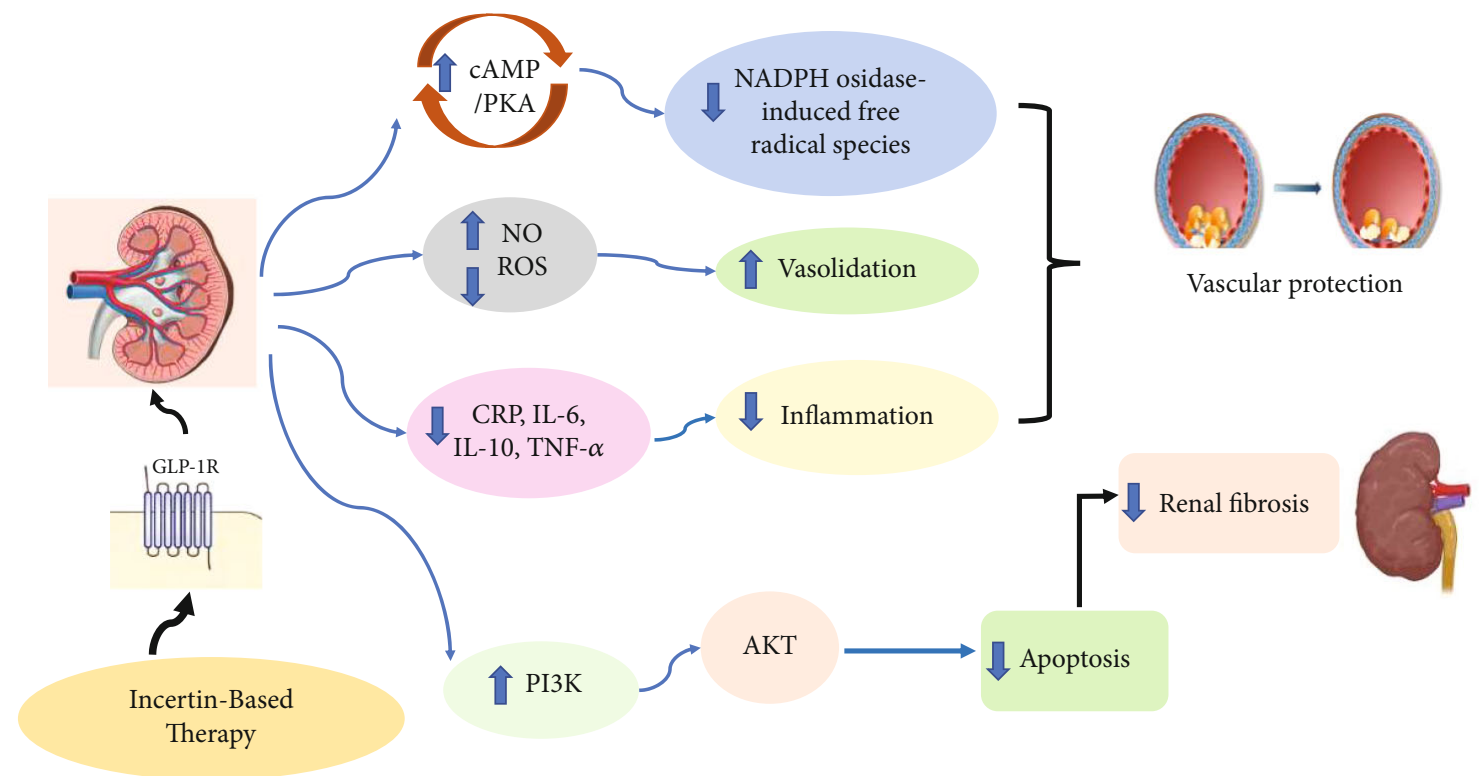

FIGURE 1: The mechanism underlying the renoprotective effects of incretin therapy (GLP-1RA and DPP-4i).

transcription of antioxidant elements, and its activation is correlated to protection against oxidative damage [13]. Oh and Jun in 2017 concluded that GLP-1RA was able to induce NRF2 activation and protect against oxidative stress [13]. Accordingly, Kim et al. reported that exendin-4 therapy activates NRF2 signaling pathways and inhibits oxidative damage in pancreatic tissues [43].

There is also direct evidence in kidney tissues of a GLP-1mediated antioxidant activity [44]. Civantos et al. in 2017 showed that the DPP-4i sitagliptin reduces oxidative stress in renal tissues by the NRF2-dependent pathway in an experimental model of DN [44]. Also, Yang et al. in 2020 found that liraglutide prevented diabetic kidney disease through several pathways as well as reversed NRF2 translocation into the nuclei whilst suppressing oxidative stress in diabetic obese rats [45]. Moreover, Liang et al. in 2020 provided further direct evidences indicating liraglutide protects against diabetic nephropathy by downregulation of TXNIP (thioredoxin-interacting protein), which acts as an oxidative stress inducer in male high fed diet mice [46]. Similarly, Wang and coworkers reported that exenatide exerts renoprotective effects by suppressing oxidative damage in diabetic rats [47]. Therefore, it has been hypothesized that improvement of renal function and reduction in albuminuria might be associated with the antioxidant properties of these agents [48-50].
4.2. Anti-Inflammatory Activity. Inflammation has a pivotal role in DN pathophysiology $[21,51,52]$, and there is evidence that GLP-1 may have anti-inflammatory activities $[53,54]$. Wu and coworkers in 2011 found that treatment with exenatide attenuated serum levels of inflammatory molecules, such as monocyte chemoattractant protein-1 (MCP1) and high-sensitivity C-reactive protein (hs-CRP), leading to lower grade inflammation in diabetic subjects [38]. In addition, Satoh-Asahara and colleagues in 2013 demonstrated that sitagliptin markedly decreased the serum levels of CRP, interleukin- (IL-) 6, IL-10, and tumor necrosis factor- (TNF-) $\alpha$ in diabetic patients [54]. Moreover, Marques and coworkers in 2014 demonstrated that sitagliptin therapy attenuated the levels of IL- $1 \beta$ and TNF- $\alpha$ and decreased the inflammatory responses in kidneys in diabetic animals [55]. Similarly, Kodera and coworkers in 2011 suggested that the renoprotective effects of GLP-1 are independent of its hypoglycemic effects and that it is completely related to its antiinflammatory activity [56]. More recently, Cappetta and colleagues showed that DPP-4 inhibition might reduce the progression of DN by suppressing the inflammatory mediators, such as TNF- $\alpha$, IL- $1 \beta$, IL-6, and MCP-1 in rats [57], suggesting a potential immunomodulatory effect for these drugs. In addition, Wang and colleagues in 2019 reported that exenatide provided protective effects against DN via alleviating 
TABLE 2: Main molecular mechanisms by which GLP-1 activity affords renoprotective effects.

\begin{tabular}{|c|c|c|}
\hline Molecular mechanisms & Effects on renal function & Ref. \\
\hline Antioxidant activity & $\begin{array}{l}\text { Decrease the levels of LDH, oxLDL, CK-MB, and MDA; induces NRF2 activity and } \\
\text { potentiates antioxidant defense system; decreases NOX activity and free radical } \\
\text { production, ameliorates oxidative damage }\end{array}$ & {$[11,13,31,41,42]$} \\
\hline $\begin{array}{l}\text { Anti-inflammatory } \\
\text { activity }\end{array}$ & $\begin{array}{l}\text { Decrease the inflammatory mediators of NF- } \kappa \mathrm{B} \text {, hs-CRP, TNF- } \alpha \text {, IL- } 1 \beta \text {, IL- } 6 \text {, and MCP-1 } \\
\text { leading to a lower rate of inflammation }\end{array}$ & {$[38,54-56]$} \\
\hline $\begin{array}{l}\text { Vascular endothelial } \\
\text { function }\end{array}$ & Induces eNOS activity and improves vascular endothelium function & {$[57,60-64,68,69]$} \\
\hline $\begin{array}{l}\text { Antiapoptotic and } \\
\text { antifibrotic effects }\end{array}$ & $\begin{array}{c}\text { Inhibits molecular pathways upstream to apoptosis and fibrosis by various pathways } \\
\text { such as TGF- } \beta 1 / \text { Smad3 and ERK1/2 signaling pathways and so protects tissues against } \\
\text { cellular death }\end{array}$ & {$[37,41,71,72,75-77]$} \\
\hline
\end{tabular}

the inflammatory responses in diabetic rats [47]. They found that exenatide reduced inflammatory markers such as TNF$\alpha$, IL-6, CRP, and CCL-5 (chemokine C-C motif ligand 5) in renal tissues [47]. Moreover, Muskiet et al. in an extensive clinical study demonstrated renoprotective effects of incretins and suggested that they provide these beneficial effects via anti-inflammatory properties [58]. These data strongly suggest that GLP-1 action might have direct renoprotective effects by at least partly suppressing inflammation $[39,54-56]$.

4.3. Vascular Protection. The level of nitric oxide (NO) bioavailability has a key role in the normal function of vascular endothelium as well as the normal-physiologic hemodynamic state [59]. In DN, NO bioavailability is reduced [33, 59]. Some studies have shown the renoprotective effects of agents via modulating $\mathrm{NO}$ synthesis and/or NOS (nitric oxide synthase) expression $[60,61]$.

Emerging evidence suggests that GLP-1 can modulate NO synthesis $[62,63]$. Barale and colleagues in 2017 reported that GLP-1 was able to modify NO bioavailability and activity in platelets [62]. Sélley and coworkers in 2014 demonstrated that exenatide decreased blood pressure and caused vasodilation in a dose-dependent manner by producing NO [64]. This NO modulating effect may be protective for the development of renal failure in diabetes [65]. Thomson and coworkers in 2017 demonstrated that exenatide modified the renal hemodynamic state and improved the glomerular filtration rate (GFR), providing renoprotective effects by a mechanism dependent on NO synthesis and bioavailability [65].

GLP-1 receptors are highly expressed in renal vessels and therefore play an important role in their function $[66,67]$. Jensen et al. in 2020 found that renal vasodilation is closely dependent on GLP-1 receptors in kidneys indicating that these receptors have significant roles in renal vasculature homeostasis and kidney function [67]. They observed that hypertensive animals with kidney dysfunction had reduced GLP-1 receptors in their renal tissues. Cappetta and colleagues in 2019 proposed that DPP-4 inhibition might protect animals from the development of renal failure by inducing endothelial nitric oxide synthase (eNOS) enzyme activity and improving endothelial function [57]. Moreover, Filippatos and Elisaf in 2013 reported that GLP-1 improved renal function modulating $\mathrm{NO}$ and regulating renal vasculature function [68]. More recently, Bjørnholm et al. in 2021 found that GLP-1 agonists have regulatory effects on the renal renin-angiotensin system and, thereby, provide modulatory effects on renal vascular [66]. These results were also confirmed in other reports [69], indicating that GLP-1 could improve renal function by modulating NO bioavailability and promoting vascular endothelial function.

4.4. Antiapoptotic and Antifibrotic Effects. GLP-1 may ameliorate DM-induced kidney injury by suppressing renal cell apoptosis and fibrosis that are increased under chronic hyperglycemia [37, 70]. In 2013, Chang and colleagues found that exenatide suppressed apoptotic pathways through PI3K/Akt (phosphoinositide 3-kinases/protein kinase B) signaling pathways [37]. Also, Pujadas and coworkers reported that the DPP-4i teneligliptin ameliorated diabetes-induced kidney tissue injury by inhibiting apoptotic pathways in human endothelial cells [41]. Moreover, Tews and colleagues in 2009 demonstrated that exendin-4 decreased cytokine-induced tissue injury by abrogating the apoptotic pathways in pancreatic beta cells [71]. Furthermore, Marques et al. in 2014 showed that GLP-1 through sitagliptin decreased apoptotic cell death and improved kidney function in diabetic animals [55].

The fibrotic process is induced by various stimuli such as free radical species and inflammatory cytokines. It plays a significant role in diabetes-induced tissue injury as well as in DN [72]. Modulating fibrosis is an attractive therapeutic option $[73,74]$. GLP-1 might modulate the fibrotic process and so reduce tissue injury [75]. In 2016, Shi et al. showed that DPP$4 \mathrm{i}$ might have renoprotective effects impacting on fibrotic cells [75]. Furthermore, Shi and coworkers in 2014 showed that linagliptin ameliorates diabetes-mediated kidney injury by lowering the rate of fibrotic processes in diabetic mice [75]. Li et al. showed that liraglutide inhibited the fibrotic process in the rat renal tubular epithelial cell line (NRK-52E) [76]. The authors suggested that liraglutide might have an impact on the renal fibrosis by reducing the activation of TGF- $\beta 1 / \mathrm{Smad} 3$ (a main mediator of fibrosis) and ERK1/2 (extracellular signalregulated kinases) signaling pathways [76]. Also, Xu et al. showed that the DPP-4i sitagliptin improved renal function via inhibition of renal fibrosis by upregulating the survival 
factor of glucose-regulated protein 78 (GRP78) and downregulating the TGF- $\beta 1$ in a dose-dependent manner [77]. Moreover, Liang et al. in 2020 found that liraglutide provided renoprotective effects by ameliorating apoptosis in diabetic mice [46]. These data suggest that GLP-1 activity can ameliorate kidney injury by suppressing cellular death via apoptotic and fibrotic processes.

\section{Conclusion}

$\mathrm{DN}$ is the most common cause of kidney dysfunction leading to end-stage renal failure requiring hemodialysis. Optimal diabetes control through therapeutic interventions may lower the risk of diabetic complications. Novel hypoglycemic agents of GLP-1R agonists and DPP-4i can provide renoprotective effects beyond their glucose-lowering effects. Their activities are mediated through GLP-1R induction mainly located in pancreatic islets' beta cells. The data strongly suggests that increased GLP-1 activity via administration of GLP-1R agonists or DPP-4i may reduce main molecular mechanisms underlying DN, such as oxidative stress, inflammation, endothelial function, and cellular death dependent on apoptosis and/or fibrosis (Table 2). Additional clinical studies are still needed to clarify the potential glucose-independent beneficial effects of GLP-1 agonists in human DN.

\section{Conflicts of Interest}

The authors clearly declare that they have no conflict of interest in this study.

\section{Acknowledgments}

The authors are thankful to the Clinical Research and Development Unit of the Baqiyatallah Hospital (Tehran, Iran).

\section{References}

[1] K. Ogurtsova, J. D. da Rocha Fernandes, Y. Huang et al., "IDF Diabetes Atlas: global estimates for the prevalence of diabetes for 2015 and 2040," Diabetes Research and Clinical Practice, vol. 128, pp. 40-50, 2017.

[2] H. Yaribeygi, N. Katsiki, A. E. Butler, and A. Sahebkar, "Effects of antidiabetic drugs on NLRP3 inflammasome activity, with a focus on diabetic kidneys," Drug Discovery Today, vol. 24, no. 1, pp. 256-262, 2019.

[3] H. Yaribeygi, F. R. Farrokhi, R. Rezaee, and A. Sahebkar, "Oxidative stress induces renal failure: a review of possible molecular pathways," Journal of Cellular Biochemistry, vol. 119, no. 4, pp. 2990-2998, 2018.

[4] H. Yaribeygi, A. E. Butler, G. E. Barreto, and A. Sahebkar, "Antioxidative potential of antidiabetic agents: a possible protective mechanism against vascular complications in diabetic patients," Journal of Cellular Physiology, vol. 234, no. 3, pp. 2436-2446, 2019.

[5] J. J. Holst and T. Vilsbøll, "Combining GLP-1 receptor agonists with insulin: therapeutic rationales and clinical findings," Diabetes, Obesity \& Metabolism, vol. 15, no. 1, pp. 3-14, 2013.

[6] J. Seufert and B. Gallwitz, "The extra-pancreatic effects of GLP-1 receptor agonists: a focus on the cardiovascular, gastro- intestinal and central nervous systems," Diabetes, Obesity \& Metabolism, vol. 16, no. 8, pp. 673-688, 2014.

[7] C. F. Deacon, E. Mannucci, and B. Ahrén, "Glycaemic efficacy of glucagon-like peptide-1 receptor agonists and dipeptidyl peptidase- 4 inhibitors as add-on therapy to metformin in subjects with type 2 diabetes-a review and meta analysis," Diabetes, Obesity \& Metabolism, vol. 14, no. 8, pp. 762-767, 2012.

[8] B. Ahren, "DPP-4 inhibitors," Best Practice \& Research. Clinical Endocrinology \& Metabolism, vol. 21, no. 4, pp. 517-533, 2007.

[9] K. S. Boye, F. T. Botros, A. Haupt, B. Woodward, and M. J. Lage, "Glucagon-like peptide-1 receptor agonist use and renal impairment: a retrospective analysis of an electronic health records database in the U.S. population," Diabetes Therapy, vol. 9, no. 2, pp. 637-650, 2018.

[10] M. C. Thomas, "The potential and pitfalls of GLP-1 receptor agonists for renal protection in type 2 diabetes," Diabetes \& Metabolism, vol. 43, pp. 2S20-2S27, 2017.

[11] Y. G. Kim, J. Byun, D. Yoon et al., "Renal protective effect of DPP-4 inhibitors in type 2 diabetes mellitus patients: a cohort study," Journal Diabetes Research, vol. 2016, article 1423191, 9 pages, 2016.

[12] C. Wang, L. Li, S. Liu et al., "GLP-1 receptor agonist ameliorates obesity-induced chronic kidney injury via restoring renal metabolism homeostasis," PLoS One, vol. 13, no. 3, article e0193473, 2018.

[13] Y. Oh and H. S. Jun, "Effects of glucagon-like peptide-1 on oxidative stress and Nrf2 signaling," International Journal of Molecular Sciences, vol. 19, no. 1, p. 26, 2018.

[14] D. Donnelly, "The structure and function of the glucagon-like peptide-1 receptor and its ligands," British Journal of Pharmacology, vol. 166, no. 1, pp. 27-41, 2012.

[15] B. Thorens, "Expression cloning of the pancreatic beta cell receptor for the gluco-incretin hormone glucagon-like peptide 1," Proceedings of the National Academy of Sciences of the United States of America, vol. 89, no. 18, pp. 8641-8645, 1992.

[16] J. S. Dillon, Y. Tanizawa, M. B. Wheeler et al., "Cloning and functional expression of the human glucagon-like peptide-1 (GLP-1) receptor," Endocrinology, vol. 133, no. 4, pp. 19071910, 1993.

[17] C. R. Underwood, P. Garibay, L. B. Knudsen et al., "Crystal structure of glucagon-like peptide-1 in complex with the extracellular domain of the glucagon-like peptide-1 receptor," The Journal of Biological Chemistry, vol. 285, no. 1, pp. 723-730, 2010.

[18] G. Song, D. Yang, Y. Wang et al., "Human GLP-1 receptor transmembrane domain structure in complex with allosteric modulators," Nature, vol. 546, no. 7657, pp. 312-315, 2017.

[19] P. Brubaker and D. Drucker, "Structure-function of the glucagon receptor family of G protein-coupled receptors: the glucagon, GIP, GLP-1, and GLP-2 receptors," Receptors and Channels, vol. 8, no. 3-4, pp. 179-188, 2002.

[20] D. Wootten, C. A. Reynolds, C. Koole et al., "A hydrogenbonded polar network in the core of the glucagon-like peptide-1 receptor is a fulcrum for biased agonism: lessons from class B crystal structures," Molecular Pharmacology, vol. 89, no. 3, pp. 335-347, 2016.

[21] H. Yaribeygi, S. L. Atkin, M. Pirro, and A. Sahebkar, “A review of the anti-inflammatory properties of antidiabetic agents providing protective effects against vascular complications in 
diabetes," Journal of Cellular Physiology, vol. 234, no. 6, pp. 8286-8294, 2019.

[22] D. J. Drucker and M. A. Nauck, "The incretin system: glucagon-like peptide-1 receptor agonists and dipeptidyl peptidase-4 inhibitors in type 2 diabetes," The Lancet, vol. 368, no. 9548, pp. 1696-1705, 2006.

[23] J. J. Meier, "GLP-1 receptor agonists for individualized treatment of type 2 diabetes mellitus," Nature Reviews. Endocrinology, vol. 8, no. 12, pp. 728-742, 2012.

[24] L. L. Baggio and D. J. Drucker, "Biology of incretins: GLP-1 and GIP," Gastroenterology, vol. 132, no. 6, pp. 2131-2157, 2007.

[25] K. A. Scott and T. H. Moran, "The GLP-1 agonist exendin-4 reduces food intake in nonhuman primates through changes in meal size," American Journal of Physiology. Regulatory, Integrative and Comparative Physiology, vol. 293, no. 3, pp. R983R987, 2007.

[26] X. Ding, N. K. Saxena, S. Lin, N. Gupta, and F. A. Anania, "Exendin-4, a glucagon-like protein-1 (GLP-1) receptor agonist, reverses hepatic steatosis in ob/ob mice," Hepatology, vol. 43, no. 1, pp. 173-181, 2006.

[27] D. Wootten, J. Simms, C. Koole et al., "Modulation of the glucagon-like peptide-1 receptor signaling by naturally occurring and synthetic flavonoids," The Journal of Pharmacology and Experimental Therapeutics, vol. 336, no. 2, pp. 540-550, 2011.

[28] A. L. Sun, J. T. Deng, G. J. Guan et al., "Dipeptidyl peptidaseIV is a potential molecular biomarker in diabetic kidney disease," Diabetes \& Vascular Disease Research, vol. 9, no. 4, pp. 301-308, 2012.

[29] P. L. Brubaker, "The glucagon-like peptides: pleiotropic regulators of nutrient homeostasis," Annals of the New York Academy of Sciences, vol. 1070, no. 1, pp. 10-26, 2006.

[30] K. Metsärinne, A. Bröijersen, I. Kantola et al., "High prevalence of chronic kidney disease in Finnish patients with type 2 diabetes treated in primary care," Primary Care Diabetes, vol. 9, no. 1, pp. 31-38, 2015.

[31] A. Aldukhayel, "Prevalence of diabetic nephropathy among type 2 diabetic patients in some of the Arab countries," International journal of health sciences, vol. 11, no. 1, pp. 1-4, 2017.

[32] M. K. Arora and U. K. Singh, "Molecular mechanisms in the pathogenesis of diabetic nephropathy: an update," Vascular Pharmacology, vol. 58, no. 4, pp. 259-271, 2013.

[33] H. Yaribeygi, M. T. Mohammadi, R. Rezaee, and A. Sahebkar, "Crocin improves renal function by declining Nox-4, IL-18, and p53 expression levels in an experimental model of diabetic nephropathy," Journal of Cellular Biochemistry, vol. 119, no. 7, pp. 6080-6093, 2018.

[34] H. Yaribeygi, M. T. Mohammadi, R. Rezaee, and A. Sahebkar, "Fenofibrate improves renal function by amelioration of NOX4, IL-18, and p53 expression in an experimental model of diabetic nephropathy," Journal of Cellular Biochemistry, vol. 119, no. 9, pp. 7458-7469, 2018.

[35] H. Yaribeygi, S. L. Atkin, A. E. Butler, and A. Sahebkar, "Sodium-glucose cotransporter inhibitors and oxidative stress: an update," Journal of Cellular Physiology, vol. 234, no. 4, pp. 3231-3237, 2019.

[36] M. C. Bunck, A. Cornér, B. Eliasson et al., "One-year treatment with exenatide vs. insulin glargine: effects on postprandial glycemia, lipid profiles, and oxidative stress," Atherosclerosis, vol. 212, no. 1, pp. 223-229, 2010.
[37] G. Chang, D. Zhang, H. Yu et al., "Cardioprotective effects of exenatide against oxidative stress-induced injury," International Journal of Molecular Medicine, vol. 32, no. 5, pp. 1011-1020, 2013.

[38] J. D. Wu, X. H. Xu, J. Zhu et al., "Effect of exenatide on inflammatory and oxidative stress markers in patients with type 2 diabetes mellitus," Diabetes Technology \& Therapeutics, vol. 13, no. 2, pp. 143-148, 2011.

[39] J. D. Vaghasiya, N. R. Sheth, Y. S. Bhalodia, and N. P. Jivani, "Exaggerated liver injury induced by renal ischemia reperfusion in diabetes: effect of exenatide," Saudi Journal of Gastroenterology, vol. 16, no. 3, pp. 174-180, 2010.

[40] G. G. Holz, "Epac: a new cAMP-binding protein in support of glucagon-like peptide-1 receptor-mediated signal transduction in the pancreatic beta-cell," Diabetes, vol. 53, no. 1, pp. 5-13, 2004.

[41] G. Pujadas, V. De Nigris, F. Prattichizzo, L. La Sala, R. Testa, and A. Ceriello, "The dipeptidyl peptidase-4 (DPP-4) inhibitor teneligliptin functions as antioxidant on human endothelial cells exposed to chronic hyperglycemia and metabolic highglucose memory," Endocrine, vol. 56, no. 3, pp. 509-520, 2017.

[42] A. Ceriello, L. Sportiello, C. Rafaniello, and F. Rossi, "DPP-4 inhibitors: pharmacological differences and their clinical implications," Expert Opinion on Drug Safety, vol. 13, Supplement 1, pp. S57-S68, 2014.

[43] M. H. Kim, E. H. Kim, H. S. Jung, D. Yang, E.-Y. Park, and H. S. Jun, "EX4 stabilizes and activates Nrf2 via PKC $\delta$, contributing to the prevention of oxidative stress-induced pancreatic beta cell damage," Toxicology and Applied Pharmacology, vol. 315, pp. 60-69, 2017.

[44] E. Civantos, E. Bosch, E. Ramírez Bustillo et al., "Sitagliptin ameliorates oxidative stress in experimental diabetic nephropathy by diminishing the miR-200a/Keap-1/Nrf2 antioxidant pathway," Diabetes, Metabolic Syndrome and Obesity: Targets and Therapy, vol. Volume 10, pp. 207-222, 2017.

[45] S. Yang, C. Lin, X. Zhuo et al., "Glucagon-like peptide-1 alleviates diabetic kidney disease through activation of autophagy by regulating AMP-activated protein kinase-mammalian target of rapamycin pathway," American Journal of PhysiologyEndocrinology and Metabolism, vol. 319, no. 6, pp. E1019E1030, 2020.

[46] R. Liang, M. Wang, C. Fu et al., "Liraglutide protects against high-fat diet-induced kidney injury by ameliorating apoptosis," Endocrine Connections, vol. 9, no. 9, pp. 946-954, 2020.

[47] X. Wang, Z. Li, X. Huang et al., "An experimental study of exenatide effects on renal injury in diabetic rats," Acta Cirurgica Brasileira, vol. 34, no. 1, 2019.

[48] A. E. El-Sahar, M. M. Safar, H. F. Zaki, A. S. Attia, and A. A. Ain-Shoka, "Sitagliptin attenuates transient cerebral ischemia/reperfusion injury in diabetic rats: implication of the oxidative-inflammatory-apoptotic pathway," Life Sciences, vol. 126, pp. 81-86, 2015.

[49] H. Mori, Y. Okada, T. Arao, and Y. Tanaka, "Sitagliptin improves albuminuria in patients with type 2 diabetes mellitus," Journal of Diabetes Investigation, vol. 5, no. 3, pp. 313319, 2014.

[50] M. A. Alam, M. R. H. Chowdhury, P. Jain, M. A. T. Sagor, and H. M. Reza, "DPP-4 inhibitor sitagliptin prevents inflammation and oxidative stress of heart and kidney in two kidney and one clip (2K1C) rats," Diabetology and Metabolic Syndrome, vol. 7, no. 1, 2015. 
[51] H. Yaribeygi, A. E. Butler, S. L. Atkin, N. Katsiki, and A. Sahebkar, "Sodium-glucose cotransporter 2 inhibitors and inflammation in chronic kidney disease: possible molecular pathways," Journal of Cellular Physiology, vol. 234, no. 1, pp. 223-230, 2019.

[52] H. Yaribeygi, S. L. Atkin, and A. Sahebkar, "Interleukin-18 and diabetic nephropathy: a review," Journal of Cellular Physiology, vol. 234, no. 5, pp. 5674-5682, 2019.

[53] L. Ferreira, E. Teixeira-de-Lemos, F. Pinto et al., "Effects of sitagliptin treatment on dysmetabolism, inflammation, and oxidative stress in an animal model of type 2 diabetes (ZDF rat)," Mediators of Inflammation, vol. 2010, Article ID 592760, 11 pages, 2010.

[54] N. Satoh-Asahara, Y. Sasaki, H. Wada et al., "A dipeptidyl peptidase-4 inhibitor, sitagliptin, exerts anti-inflammatory effects in type 2 diabetic patients," Metabolism, vol. 62, no. 3, pp. 347-351, 2013.

[55] C. Marques, C. Mega, A. Gonçalves et al., "Sitagliptin prevents inflammation and apoptotic cell death in the kidney of type 2 diabetic animals," Mediators of Inflammation, vol. 2014, Article ID 538737, 15 pages, 2014.

[56] R. Kodera, K. Shikata, H. U. Kataoka et al., "Glucagon-like peptide-1 receptor agonist ameliorates renal injury through its anti-inflammatory action without lowering blood glucose level in a rat model of type 1 diabetes," Diabetologia, vol. 54, no. 4, pp. 965-978, 2011.

[57] D. Cappetta, L. P. Ciuffreda, A. Cozzolino et al., "Dipeptidyl peptidase 4 inhibition ameliorates chronic kidney disease in a model of salt-dependent hypertension," Oxidative Medicine and Cellular Longevity, vol. 2019, Article ID 8912768, 13 pages, 2019.

[58] M. H. Muskiet, L. Tonneijck, Y. Huang et al., "Lixisenatide and renal outcomes in patients with type 2 diabetes and acute coronary syndrome: an exploratory analysis of the ELIXA randomised, placebo- controlled trial," The Lancet Diabetes and Endocrinology, vol. 6, no. 11, pp. 859-869, 2018.

[59] U. Forstermann and T. Munzel, "Endothelial nitric oxide synthase in vascular disease," Circulation, vol. 113, no. 13, pp. 1708-1714, 2006.

[60] M.-S. Zhou, I. H. Schuman, E. A. Jaimes, and L. Raij, "Renoprotection by statins is linked to a decrease in renal oxidative stress, TGF- $\beta$, and fibronectin with concomitant increase in nitric oxide bioavailability," American Journal of Physiology. Renal Physiology, vol. 295, no. 1, pp. F53-F59, 2008.

[61] M. K. Shirazi, A. Azarnezhad, M. F. Abazari et al., "The role of nitric oxide signaling in renoprotective effects of hydrogen sulfide against chronic kidney disease in rats: involvement of oxidative stress, autophagy and apoptosis," Journal of Cellular Physiology, vol. 234, no. 7, pp. 11411-11423, 2019.

[62] C. Barale, S. Buracco, F. Cavalot, C. Frascaroli, A. Guerrasio, and I. Russo, "Glucagon-like peptide 1-related peptides increase nitric oxide effects to reduce platelet activation," Thrombosis and Haemostasis, vol. 117, no. 6, pp. 1115-1128, 2017.

[63] S. Yamane and N. Inagaki, "Regulation of glucagon-like peptide-1 sensitivity by gut microbiota dysbiosis," Journal of Diabetes Investigation, vol. 9, no. 2, pp. 262-264, 2018.

[64] E. Sélley, S. Kun, I. A. Szijártó et al., "Exenatide induces aortic vasodilation increasing hydrogen sulphide, carbon monoxide and nitric oxide production," Cardiovascular Diabetology, vol. 13 , no. 1 , p. $69,2014$.
[65] S. C. Thomson, A. Kashkouli, Z. Z. Liu, and P. Singh, "Renal hemodynamic effects of glucagon-like peptide-1 agonist are mediated by nitric oxide but not prostaglandin," American Journal of Physiology. Renal Physiology, vol. 313, no. 4, pp. F854-F858, 2017.

[66] K. D. Bjørnholm, M. E. Ougaard, G. F. Skovsted, L. B. Knudsen, and C. Pyke, "Activation of the renal GLP-1R leads to expression ofRen1in the renal vascular tree," Endocrinology, Diabetes \& Metabolism, vol. 4, no. 3, 2021.

[67] E. P. Jensen, S. Møller, A. V. Hviid et al., "GLP-1-induced renal vasodilation in rodents depends exclusively on the known GLP-1 receptor and is lost in prehypertensive rats," American Journal of Physiology. Renal Physiology, vol. 318, no. 6, pp. F1409-F1417, 2020.

[68] T. D. Filippatos and M. S. Elisaf, "Effects of glucagon-like peptide-1 receptor agonists on renal function," World Journal of Diabetes, vol. 4, no. 5, pp. 190-201, 2013.

[69] M. Haluzík, J. Frolík, and I. Rychlík, "Renal effects of DPP-4 inhibitors: a focus on microalbuminuria," International Journal of Endocrinology, vol. 2013, Article ID 895102, 7 pages, 2013.

[70] K. Kanasaki, S. Shi, M. Kanasaki et al., "Linagliptin-mediated DPP-4 inhibition ameliorates kidney fibrosis in streptozotocin-induced diabetic mice by inhibiting endothelial-to-mesenchymal transition in a therapeutic regimen," Diabetes, vol. 63, no. 6, pp. 2120-2131, 2014.

[71] D. Tews, S. Lehr, S. Hartwig, A. Osmers, W. Passlack, and J. Eckel, "Anti-apoptotic action of exendin-4 in INS-1 beta cells: comparative protein pattern analysis of isolated mitochondria," Hormone and Metabolic Research, vol. 41, no. 4, pp. 294-301, 2009.

[72] T. Wynn, "Cellular and molecular mechanisms of fibrosis," The Journal of Pathology, vol. 214, no. 2, pp. 199-210, 2008.

[73] Y. Liu, "Renal fibrosis: new insights into the pathogenesis and therapeutics," Kidney International, vol. 69, no. 2, pp. $213-$ 217, 2006.

[74] Y. Liu, "Cellular and molecular mechanisms of renal fibrosis," Nature Reviews. Nephrology, vol. 7, no. 12, pp. 684-696, 2011.

[75] S. Shi, D. Koya, and K. Kanasaki, "Dipeptidyl peptidase-4 and kidney fibrosis in diabetes," Fibrogenesis \& Tissue Repair, vol. 9, no. 1, 2016.

[76] Y. K. Li, D. X. Ma, Z. M. Wang et al., "The glucagon-like peptide-1 (GLP-1) analog liraglutide attenuates renal fibrosis," Pharmacological Research, vol. 131, pp. 102-111, 2018.

[77] J. Xu, J. Wang, Y. Cheng et al., "Glucagon-like peptide-1 mediates the protective effect of the dipeptidyl peptidase IV inhibitor on renal fibrosis via reducing the phenotypic conversion of renal microvascular cells in monocrotaline-treated rats," BioMed Research International, vol. 2018, Article ID 1864107, 14 pages, 2018. 